\title{
KNOWLEDGE OF BASIC LIFE SUPPORT AMONG FINAL YEAR DENTAL STUDENTS OF BPKIHS
}

\author{
Anjani Kumar Yadav ${ }^{1 *}$, Mehul Rajesh Jaisani ${ }^{2}$, Ashok Dongol $^{3}$, Pradeep Acharya $^{3}$
}

\begin{abstract}
Affiliation
1. Assistant Professor, Department of Oral and Maxillofacial Surgery B. P. Koirala Institute of Health Sciences, Dharan, Nepal

2. Additional Professor, Department of Oral and Maxillofacial Surgery B. P. Koirala Institute of Health Sciences, Dharan, Nepal

3. Associate Professor, Department of Oral and Maxillofacial Surgery B. P. Koirala Institute of Health Sciences, Dharan, Nepal
\end{abstract}

\section{ARTICLE INFO}
Received : 12 Dec., 2020
Accepted : 06 Sep., 2021
Published : 04 Nov. 2021

(c) Authors retain copyright and grant the journal right of first publication with the work simultaneously licensed under Creative Commons Attribution License CC - BY 4.0 that allows others to share the work with an acknowledgment of the work's authorship and initial publication in this journal.

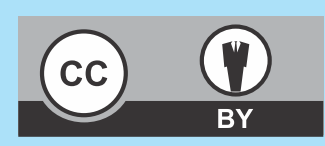

ORA 245

D.OI: https://doi.org/10.3126/bjhs.v6i2.40305

* Corresponding Author

Dr Anjani Kumar Yadav

Assistant Professor

Department of Oral and Maxillofacial Surgery

B. P. Koirala Institute of Health Sciences, Dharan, Nepal

Email: kumaryadavanjani@gmail.com

ORCID: https://orcid.org/0000-0002-9734-3688

\section{Citation}

Anjani Kumar Yadav, Mehul Rajesh Jaisani, Ashok Dongol, Pradeep Acharya. Knowledge of Basic Life Support among Final Year Dental Students of BPKIHS. BJHS 2021;6(2)15. 1432-1435.

\section{ABSTRACT}

Introduction

The chance of survival of a victim after cardiac arrest/ foreign-body airway obstruction is doubled by early institution of Basic Life Support (BLS). Besides medical doctors, dental doctors might also encounter the patients in emergency situation requiring BLS, especially during peripheral district teaching hospital posting in internship.

\section{Objectives}

The objective of this study was to assess the level of knowledge about BLS among final year dental students of BPKIHS.

\section{Methodology}

In this cross-sectional study, structured questionnaires were distributed to BDS final year students (purposive sampling, sample size $=53$ ). Each question responded correctly was awarded as point +1 and total points were calculated by adding all the correct answers. The collected data were entered in Microsoft excel 2010 and descriptive analysis was done by SPSS 16.

\section{Result}

Out of 53 questionnaires distributed, 49 were responded and returned (response rate $=92.45 \%$ ). Twenty participants were male and twenty-nine were female. Four participants had taken BLS training in the past. Only twenty participants scored $\geq 50 \%$ and none of the participant scored $\geq 75 \%$. Only one question was responded correctly by $100 \%$ participants. Ten questions were responded correctly by $\geq 50 \%$ participants. Although $65.3 \%$ participants were aware about high quality CPR, only $49 \%$ knew the exact location of chest compression. The chest compression to ventilation ratio for each of single rescuer and two rescuers was known by 20 participants $(40.8 \%)$ and 28 participants $(57.1 \%)$ respectively.

\section{Conclusion}

Knowledge of BLS is poor among BDS final year students.

\section{KEYWORDS}

Basic life support, Final year students, Knowledge 


\section{INTRODUCTION}

Basic Life Support (BLS) includes identification of signs of sudden cardiac arrest, heart attack and stroke; early institution of cardiopulmonary resuscitation (CPR) and rapid defibrillation with an automated external defibrilator. ${ }^{1}$ Cardiopulmonary resuscitation is a lifesaving process that improves the survival rates of the patients that suffer from cardiac arrest. ${ }^{2}$ Similarly, the survival rate after cardiac arrest is further improved by early institution of good quality CPR and early defibrillation. The survival rate after cardiac arrest was found to be $67 \%$ if all the interventions were done immediately after collapse, but the chances of survival decline by $5.5 \%$ for every minute delay in CPR, defibrillation and definitive care. ${ }^{3}$ Immediate recognition and activation, early CPR, and rapid defibrillation (when appropriate) are the first three BLS links in the adult Chain of Survival but identification of cardiac arrest is not straight forward and any confusion from rescuer part can result in delay in institution of CPR and thus the precious time is lost that might decrease the chances of survival. ${ }^{4}$ All the health care professionals including doctors, nurses and paramedical persons should know how to perform BLS as they encounter such situation very often. The students of each and every health science college are the building block of future health care system of any country and hence their knowledge of BLS is crucial. Lack of structured training has been identified as the main reason of poor knowledge about BLS. ${ }^{5}$ Similarly, BDS (Bachelor of Dental Surgery) students of B. P. Koirala Institute of Health Science (BPKIHS) immediately after passing the final year exam are posted in various district/zonal hospital during their internship and they may encounter a situation where they have to perform this life saving procedures and they cannot escape just because they are dental doctors. It has been reported that there have been poor training and low level of confidence among undergraduate students even in France and UK. ${ }^{6,7}$ No such report has been found in dental undergraduate students in Nepal. The rationale of this study was to assess the level of knowledge about BLS among dental (BDS) final year students of BPKIHS to gather information for the effective organization of training of BLS before entering internship.

\section{METHODOLOGY}

It was a questionnaire based cross-sectional study conducted among the final year dental students of BPKIHS. All the students of BDS final year (2014 batch) giving consent to participate in the study were included. Ethical clearance was taken from the Institutional Review Committee (IRC) of BPKIHS. Procedures of the research were explained to the participants and informed written consent was taken from each participant. A list of BDS final year students was compiled from the attendance register of BPKIHS (purposive sampling, sample size $=53$ ). Structured questionnaires were delivered to all on the list by hand on $20 / 03 / 2019$, one month before appearing the final exam assuming that the students had gained the optimum knowledge at that time. The questionnaires contained twenty six multiple choice questions and were designed to collect data about age, sex, BLS training in the past and knowledge about BLS. Most of the questionnaires were returned on the same day of distribution and for those who did not return, a reminder message was send to each of them via mobile on the fifth day after distribution. The questionnaires were collected over a period of one week and the collected questionnaires were analyzed. Each question responded correctly was awarded as point +1 and total points were calculated by adding all the correct answers. The collected data were entered in Microsoft excel 2010 and descriptive analysis was done by SPSS 16 . The scores were categorized as very poor $(<30 \%)$, poor (30-45\%), average (46-55\%), good (56-65\%), very good (66-75\%) and excellent $(>75 \%)^{.}$

\section{RESULTS}

Out of fifty three questionnaires distributed, forty nine were returned to the investigator and the thus the response rate from the participants was $92.45 \%$. Out of 49 participants, only $4(8.2 \%)$ participants had taken BLS training in the past (Figure 1). The correct response to each question is shown in Table 1. Only one question (full form of BLS) was responded correctly by $100 \%$ participants while only three participants (6.1\%) knew the full form of AED. Ten questions were responded correctly by $50 \%$ or more participants and three questions were responded correctly by less than $10 \%$ participant. Only thirty percent (30.6\%) of the participant knew that EMS should be activated immediately after confirmation of unresponsiveness and only six percent were aware that CPR is not aimed to restart the heart. Although

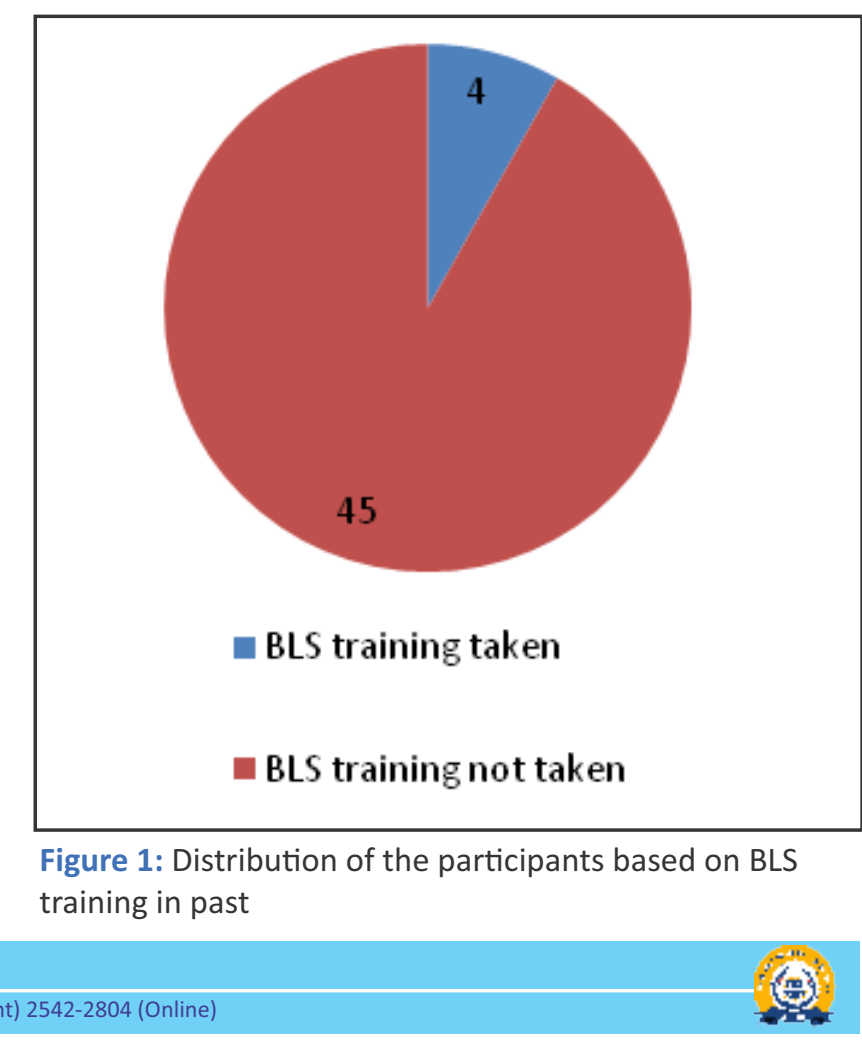


Table 1: Distribution of correct response to each question

\begin{tabular}{|c|c|c|}
\hline Q. N. & Questions & $\begin{array}{c}\text { Correct } \\
\text { Response }\end{array}$ \\
\hline 1 & What is the full form of "BLS"? & $48(98 \%)$ \\
\hline 2 & What do you understand by CPR? & $49(100 \%)$ \\
\hline 3 & CAB in CPR stands for? & $46(93.9 \%)$ \\
\hline 4 & $\begin{array}{l}\text { When you find someone unresponsive in the middle of the } \\
\text { road, what will be your first response? (Note: You are } \\
\text { alone there) }\end{array}$ & $31(63.3 \%)$ \\
\hline 5 & $\begin{array}{l}\text { If you confirm somebody is not responding to you even } \\
\text { after shaking and shouting at him, what will be your } \\
\text { immediate action? }\end{array}$ & $15(30.6 \%)$ \\
\hline 6 & CPR aims to restart the heart (Yes or No) & $6(12.2 \%)$ \\
\hline 7 & $\begin{array}{l}\text { The critical characteristics of high -quality CPR include } \\
\text { which of the following? }\end{array}$ & $32(65.3 \%)$ \\
\hline 8 & What is the location for chest compression? & $24(49 \%)$ \\
\hline 9 & What is the location for chest compression in infants? & $29(59.2 \%)$ \\
\hline 10 & $\begin{array}{l}\text { If you do not want to give mouth } \quad \text {-to-mouth CPR, the } \\
\text { following can be done EXCEPT }\end{array}$ & $14(28.6 \%)$ \\
\hline 11 & How do you give rescue breathing in infants? & $5(10.2 \%)$ \\
\hline 12 & $\begin{array}{l}\text { What is the rate of compressions per minute as specified in } \\
\text { the } 2017 \text { American Heart Association guidelines? }\end{array}$ & $22(44.9 \%)$ \\
\hline 13 & The correct depth of compression for an adult patient is & $29(59.2 \%)$ \\
\hline 14 & Depth of compression in Children during CPR & $24(49 \%)$ \\
\hline 15 & Depth of compression in neonates during CPR & $19(38.8 \%)$ \\
\hline 16 & How long should a pulse check last? & $24(49 \%)$ \\
\hline 17 & Where should you check for a pulse in an adult? & $20(40.8 \%)$ \\
\hline 18 & Infants responsiveness is checked by & $37(75.5 \%)$ \\
\hline 19 & $\begin{array}{l}\text { An infant's pulse should be checked by which } \\
\text { artery? }\end{array}$ & $2(4.1 \%)$ \\
\hline 20 & $\begin{array}{l}\text { In adults, the chest compression and ventilation } \\
\text { ratio for single rescuer CPR is }\end{array}$ & $20(40.8 \%)$ \\
\hline 21 & $\begin{array}{l}\text { In children the chest compression and ventilation } \\
\text { ratio for } 2 \text { rescuer CPR is }\end{array}$ & $28(57.1 \%)$ \\
\hline 22 & What does abbreviation AED stands for? & $3(6.1 \%)$ \\
\hline 23 & The proper steps for operating an AED are: & $9(18.4 \%)$ \\
\hline 24 & $\begin{array}{l}\text { You are witnessing an adult unresponsive victim } \\
\text { who has been submerged in fresh water and just } \\
\text { removed from it. He has spontaneous breathing, but } \\
\text { he is unresponsive. What is the first step? (need of } \\
\text { recovery position) }\end{array}$ & $4(8.2 \%)$ \\
\hline 25 & $\begin{array}{l}\text { You are witnessing an infant who suddenly started } \\
\text { choking while he was playing with the toy, you have } \\
\text { confirmed that he is unable to cry (or) cough, what } \\
\text { will be your first response? }\end{array}$ & $29(59.2 \%)$ \\
\hline 26 & $\begin{array}{l}\text { If you and your friend are having food in a canteen } \\
\text { and sud denly your friend starts expressing } \\
\text { symptoms of choking, what will be your first } \\
\text { response? (first response of choking in adult) }\end{array}$ & $11(22.4 \%)$ \\
\hline
\end{tabular}

sixty-five percent $(65.3 \%)$ of the participants were aware about high quality CPR, only $49 \%$ knew about the exact location of chest compression. The chest compression to ventilation ratio for single rescuer was known by 20 participants $(40.8 \%)$ and that for two rescuers was known by 28 participants (57.1\%). Similarly, the correct depth of chest compression in each of adults, children and infants was known by $29(59.2 \%), 24(49 \%)$ and $19(38.8 \%)$ participants respectively. Although 37 participants (75.5\%) knew how to check infant responsiveness, only two participants (4.1\%) knew the site of pulse check and only 5 (10.2\%) participants knew how to give rescue breathing in infant. Out of 49 participants, only twenty participants had scored $50 \%$ or more and none had scored $75 \%$ or above. Similarly, two participants had scored even less than $20 \%$. The percentage range scored by the previous BLS training participants was 38.5 to 46 .1. While categorizing the score, 4 participants had very poor score, 18 had poor and average scores each. Five participants had good score and four had very good scores; however, none of the participants had excellent score (Table 2).
Table 2: Number of participants as per score categories

\begin{tabular}{lc}
\hline \multicolumn{1}{c}{ Score category } & No. of participants \\
\hline Very poor $(<30 \%)$ & 4 \\
\hline Poor $(>30-45 \%)$ & 18 \\
\hline Average $(>45-55 \%)$ & 18 \\
\hline Good $(>55-65 \%)$ & 5 \\
\hline Very good $(>65-75 \%)$ & 4 \\
\hline Excellent $(>75 \%)$ & 0 \\
\hline
\end{tabular}

\section{DISCUSSION}

The aim of Basic life support training is to immediately identify the victims of cardiac arrest and foreign body airway obstruction and manage with cardiopulmonary resuscitation and defibrillation as early support of ventilation and circulation restores the blood and oxygen supply to vital organs and prevent from being damaged permanently. ${ }^{9}$ The theoretical knowledge and practical skills of BLS are the main determinant for the successful execution of CPR in emergency situation. ${ }^{8}$ The procedures of BLS are simple but systematic and it should be known to every layman. Developed countries have already recommended BLS training even for high school students nearly a decade ago. ${ }^{10}$ However; it has not been made easily available even for the medical and paramedical persons in Nepal till date. Many medical/dental and paramedical students might not learn even the basic knowledge of this essential and life-saving procedures in class with hands-on practice during their undergraduate study period and they remain incompetent to perform CPR even after graduation. The situation is same in dental students of BPKIHS but they are expected to perform CPR from the very first day of their internship as they are posted in peripheral district teaching hospital. Similarly, low confidence among medical students in performing CPR has also been reported from Europe. ${ }^{11}$ The present study also revealed that the participants have inadequate knowledge on BLS. None of the participants has scored even $70 \%$ and only one question (full form of BLS) was responded correctly by all participants. Only twenty participants scored $50 \%$ or more. Ten questions were responded correctly by $50 \%$ or more participants. Although there is a study in which participants who have received training in class have fairly higher score of knowledge regarding BLS as compared to non-trained, all four participants in the present study who had taken BLS training in the past had scored less than $50 \%{ }^{8}$ As per a study conducted by Cooper S et al, those attending immediate life support had a significantly higher knowledge score in beginning of the course as compared to the group attending BLS course that indicates that the preparatory course manual had been beneficial. Knowledge did not decline as much as the skill did after six month of training; however, it remained higher than pre-course level. ${ }^{12}$ Further, before conducting a BLS training, the level of self-confidence among the students regarding management of cardiac arrest need to be assessed as the self-perception of qualification in BLS is found to be poor. ${ }^{11}$ Thus, It is essential to standardize training in BLS to make it more retentive and mandatory component 
of all medical, dental, nursing and other paramedical students. ${ }^{13}$ This study also has limitations as it is based on a questionnaire which serves as an indicator of purely theoretical knowledge as the theoretical knowledge does not necessarily indicate that the participants can perform well in during CPR in real world. Although a theoretical test cannot replace a practical test for the assessment of an individual, it is a viable alternative as a tool to estimate and compare the efficacy of psychomotor skills, especially in group training programs. ${ }^{14}$

\section{CONCLUSION}

Knowledge of BLS is poor among the BDS final year students. Even the knowledge of participants who had taken BLS training in the past ranged from poor to average.

\section{RECOMMENDATION}

Multi Centre study should be conducted to assess the knowledge of BLS among the BDS final year students of Nepal.

\section{REFERENCES}

1. Berg RA, Hemphill R, Abella BS, Aufderheide TP, Cave DM, Hazinisk MF, Lerner EB, Rea TD, Sayre MR, Swor RA. Part 5: Adult basic life support: 2010 American Heart Association guidelines for cardiopulmonary resuscitation and emergency cardiovascular care. Circulation. 2010; Nov; 122(suppl 3): s685-s705. DOI:10.1161/ CIRCULATIONAHA.110.970939

2. Sasson C, Rogers MA, Dahl J, Kellerman AL. Predictors Of Survival From Out-Of-Hospital Cardiac Arrest: A Systematic Review And Meta-Analysis. Circ Cardiovasc Qual Outcomes 2010; Jan; 3(1): 63-81. DOI: 10.1161/CIRCOUTCOMES.109.889576

3. Larsen MP, Eisenberg MS, Cummins RO, Hallstrom AP: Predicting survival from out-of-hospital cardiac arrest: A graphic model. Ann Emerg Med. 1993; Nov; 22(11):1652-1658. DOI: 10.1016/s01960644(05)81302-2

4. Sharma R, Attar NR. Adult basic life support (BLS) awareness and knowledge among medical and dental interns completing internship from deemed university. NitteUniv J Health Sci.2012; Sep; 3(3):6-13. DOI:10.1055/S-0040-1703580

5. Aroor AR, Saya RP, Attar NR, Saya GK, Ravinanthanan M. Awareness about basic life support and emergency medical services and its associated factors among students in a tertiary care hospital in South India. J Emerg Trauma Shock. 2014; Jul; 7(3):166-9. DOI: 10.4103/0974-2700.136857

6. Casey WF. Cardiopulmonary resuscitation: a survey of standards among junior hospital doctors. J R Soc Med. 1984; Nov; 77(11): 921 4. DOI: 10.1177/014107688407701105.

7. Freund Y, Duchateau FX, Baker EC, Goulet H, Carreira S, Schmidt M, Riou B, Rouby JJ, Duguet A.Self-perception of knowledge and confidence in performing basic life support among medical students. Eur J Emerg Med. 2013; Jun; 20(3):193-6. DOI: 10.1097/ MEJ.0b013e328355fd59

8. Yunus MD, Mishra A, Karim HMR, Raphael V, Ahmed G, Myrthong CE. Knowledge, attitude and practice of basic life support among junior doctors and students in a tertiary care medical institute. Int J Res Med Sci. 2015; Jan; 3(12): 3644-3650. DOI:10.18203/23206012. ijrms20151416

\section{LIMITATION OF THE STUDY}

Being a single Centre study findings of this study cannot be generalized to all the BDS final year students.

\section{ACKNOWLEDGEMENT}

We would like to acknowledge all the BDS final year students of BPKIHS for participating in this study. We are also grateful to our junior residents and other staffs of the department of oral and maxillofacial surgery for constantly supporting in this study.

\section{CONFLICT OF INTEREST}

All the authors have no conflict of interest to declare

\section{FINANCIAL DISCLOSURE}

None

9. Baisakhiya S, Dwivedi M, Baisakhiya N. Awareness about basic life support among undergraduate interns of medical, dental, and Physiotherapy College of Maharishi Markandeshwar University, Mullana, Ambala.International Journal of Medical Science and public health. 2017; Jan; 6(9): 1398-1400. DOI: 10.5455/ijmsph. 2017. 061730707201

10. Chamberlain DA, Hazinski MF. European Resuscitation Council; American Heart Association; Heart and Stroke Foundation of Canada; Resuscitation Council of Southern Africa; Australia and New Zealand Resuscitation Council; Consejo Latino-Americano de Resusucitación. Education in resuscitation: An ILCOR symposium: Utstein Abbey: Stavanger, Norway: June 22-24, 2001. Circulation. 2003; Nov; 108(20): 2575-94. DOI: 10.1161/01.CIR. 0000099898. 11954.3B

11. Freund Y, Duchateau FX, Baker EC, Goulet H, Carreira S, Schmidt M, Riou B, Rouby JN, Duguet A. Self-perception of knowledge and confidence in performing basic life support among medical students. Eur J Emerg Med. 2013; Jun; 20(3):193-6.DOI: 10.1097/MEJ.0b013e $328355 f d 59$

12. Cooper S, Johnston E, Priscott D. Immediate Life support Training Impact in a Primary Care Setting? Resuscitation. 2007; Jan; 72(1): 9299. DOI: 10.1016/j.resuscitation.2006.06.004

13. Steen PA, Kramer-Johansen J. Improving cardiopulmonary resuscitation quality to ensure survival. CurrOpinCrit Care 2008; Jun; 14(3):299-304.DOI: 10.1097/MCC.0b013e3282f827d3

14. Kramer AW, Jansen JJ, Zuithoff P, Düsman H, Tan LH, Grol RP, Van der $\mathrm{CM}$. Predictive validity of a written knowledge test of skills for an OSCE in postgraduate training for general practice. Med Educ. 2002; Sep; 36(9):812-9. DOI: 10.1046/j.1365-2923.2002.01297.x 